\title{
CZECH TECHNOLOGY PLATFORM ON INDUSTRIAL SAFETY
}

At the beginning of June 2007 the Faculty of Safety Engineering founded the Czech Technology Platform on Industrial Safety o.s. (CZ-TPIS). The 1st meeting of the General A ssembly launched the activity of this national platform in accordance with the already operating European Technology Platform on Industrial Safety (ETPIS).

Key words: technology platform, industrial safety

\section{European Technology Platform on Industrial Safety}

In the year 2004 the European Technology Platform on Industrial Safety (ETPIS - Safety for Sustainable European Industry Growth) was founded with a view to bring together professionals concerned with these problems and influence future researches into industrial safety. The Platform is divided into 5 Focus Groups and 4 HUBs (see Fig. 1). The Platform claims 270 professionals from 190 European organizations. The Platform has prepared the Strategic Research Agenda that contains short, medium and long- term objectives and priorities. More information is available at www.industrialsafety-tp.org.

At Platform meetings, a requirement for the establishment of industrial safety national platforms, which already operate, for example, in Spain, France, Italy, Poland and other countries, appears. The national platforms are of importance to close liaison with the European Platform in the specification of research topics to be addressed in the future. The Faculty of Safety Engineering of VŠB-Technical University of Ostrava has undertaken the role of

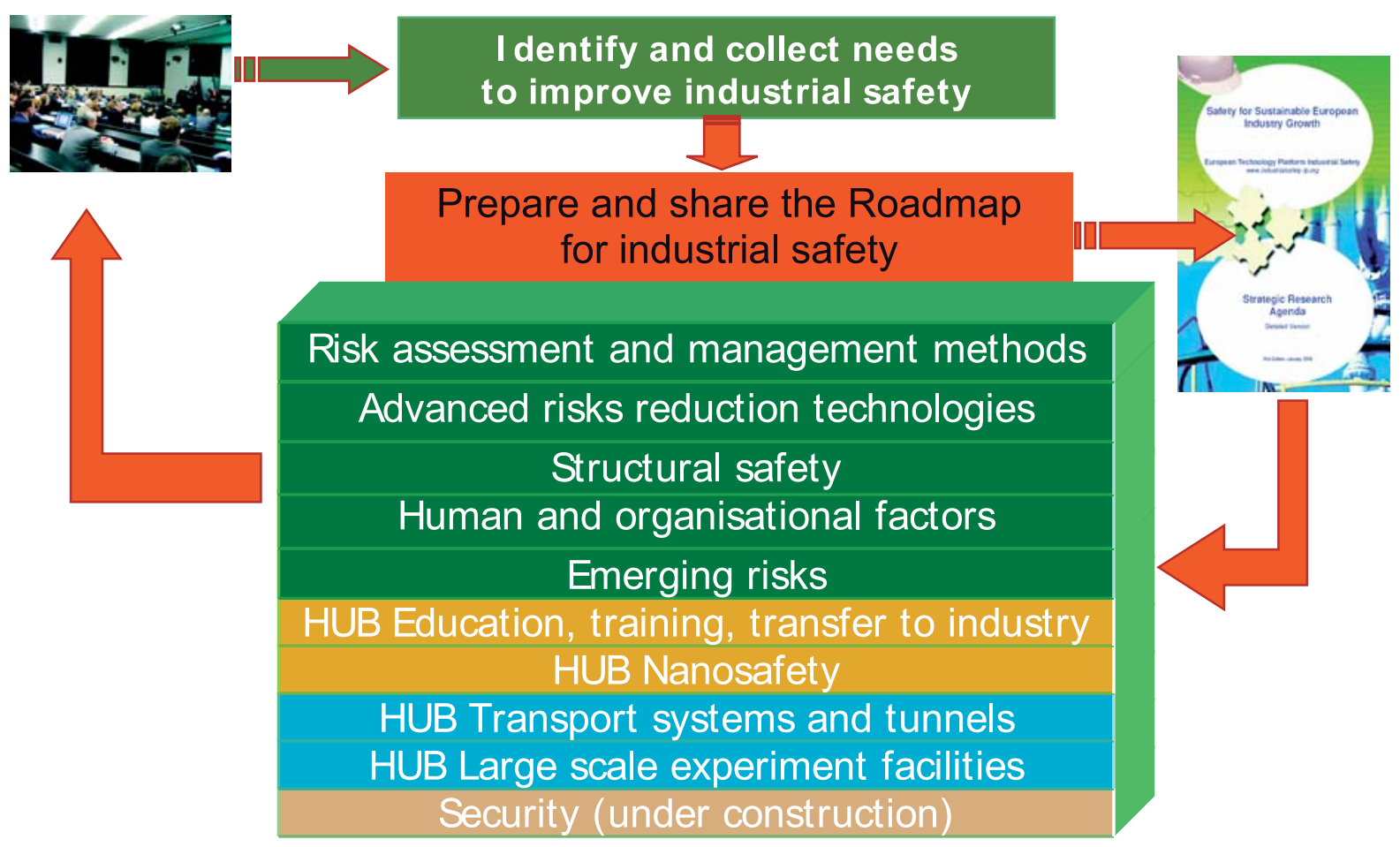

Fig. 1 Operating ETPIS to defragment $R \& D$

\footnotetext{
* Ales Bernatik, Katerna Sikorova

VSB-Technical University of Ostrava, Faculty of Safety Engineering, Ostrava-Vyskovice, Czech Republic, E-mail: ales.bernatik@vsb.cz
} 
co-ordinator for the establishment of the Technological Platform on Industrial Safety in the Czech Republic on the basis of its membership of the European Technology Platform.

\section{Czech Technology Platform on Industrial Safety}

The Czech Technology Platform on Industrial Safety is a voluntary, independent community bringing its members together on the basis of a common interest. Its mission is to provide support to the organizations that promote development in industrial safety in the Czech Republic, to identify jointly national interests in the area of industrial safety, and to enforce uniformly these interests at the European level. Any physical or legal entity wanting to support the Platform and agreeing with the Statutes of CZ-TPIS can become a member of the Platform.

The Platform is headed by the Executive Board composed of representatives of research and scientific institutions, state authorities and universities, industries and other significant organizations. The Focus Groups led by professionals in the areas concerned, and established to co-ordinate specific priorities, with links to relevant parties interested form the cornerstone. The Executive Board of the Platform, which is an executive board of CZ-TPIS, carries out the administrative control and organization of CZ-TPIS. Its members are elected by the General Assembly from a number of Platform members. The check and audit body of the Platform is the Check Commission. The supreme body of CZ-TPIS is then the General Assembly that is formed by all the members of the Platform (see Fig. 2).

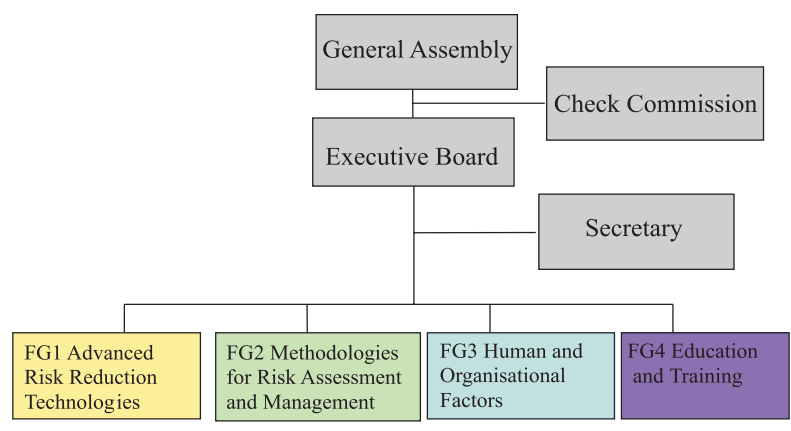

Fig. 2 Organizational structure of CZ-TPIS

\section{Conclusion}

The objectives of the Czech Technology Platform on Industrial Safety are to incorporate the Czech Republic into the ETPIS main activities, to disseminate acquired knowledge and experience in the Czech industries, and thus to achieve an increase in industrial safety and competitiveness in the Czech Republic. The establishment of CZ-TPIS will thus make it possible to interconnect the interests of industrial enterprises, research and scientific workplaces, universities and others with the interests of state authorities. Another objective of this community being founded is the more intensive participation of Czech partners in projects of the European Union's Seventh Framework Programme and other national and international projects, and in this way to contribute to the solving of issues of industrial safety in the Czech Republic. More information can be found at the web pages of the Platform at www.cztpis.cz. 